\title{
Redo Fundoplication in Infants and Children With Recurrent Gastroesophageal Reflux
}

\author{
By Michael J. Wheatley, Arnold G. Coran, John R. Wesley, Keith T. Oldham, and Richard H. Turnage \\ Ann Arbor, Michigan
}

\begin{abstract}
- The Nissen fundoplication is well established as the surgical treatment for medically refractory gastroesophageal reflux (GER) in childhood. Recurrent GER following fundoplication is a challenging problem with a reported incidence ranging from $0 \%$ to $12 \%$. From January 1974 to January 1989, 286 children have been treated for GER with Nissen fundoplication and gastrostomy tube placement at the University of Michigan C.S. Mott Children's Hospital; 242 of these children have been followed for an average of 30 months, the remaining 44 have been lost to follow-up. Twenty-nine children $(12 \%)$. have developed recurrent reflux following fundoplication. Medical management with thickened upright feelings, gastrostomy feedings, or gastrojejunostomy tube feedings has been successful for 11 children with control of reflux symptoms. Five additional ohildren who were treated nonoperatively died of coexistant medical problems within $\mathbf{2}$ months following documentation or recurrent reflux. The remaining 13 children have required redo fundoplication for wrap disruption or herniation, and an additional six children, initially treated at other institutions, have also undergone redo fundoplications. One other child treated at this hospital required redo fundoplication for a postoperative partial gastric volvulus causing gastric outlet obstruction. Of the $\mathbf{2 0}$ children who have undergone a second Nissen fundoplication, $16(80 \%)$ are doing well without recurrent GER. Four children have developed recurrent GER with wrap disruption; 1 is doing well following a third fundoplication, 2 have been managed successfully with continuous feedings via gastrojejunostomy feeding tubes, and a fourth child died of complications related to a recurrent tracheoesophageal fistula. Conservative management with gastrojejunal tube feedings should be considered in the initial management of children with recurrent GER following fundoplication. If necessary, redo Nissen fundoplication, although technically difficult, is associated with a good outcome in the majority of children and is indicated for refractory recurrent GER following a failed antireflux procedure.
\end{abstract}

Copyright $\odot 1991$ by W.B. Saunders Company

INDEX WORDS: Gastroesophageal reflux, recurrent; fundoplication.

7 THE NISSEN fundoplication is well established as the surgical treatment for medically refractory gastroesophageal reflux (GER) occurring in child-

From the Division of Pediatric Surgery, Department of Surgery, University of Michigan Medical School, and C.S. Mott Children's Hospital, Ann Arbor, MI.

Presented at the 23rd Annual Meeting of the Pacific Association of Pediatric Surgeons, Kona, Hawaii, June 3-6, 1990.

Address reprint requests to Amold G. Coran, MD, Mott Children's

Hospital, Room F7516, Box 0245, Ann Arbor, MI 48109.

Copyright $\odot 1991$ by W.B. Saunders Company

$0022-3468 / 91 / 2607-0002 \$ 03.00 / 0$ hood. Several studies have documented the efficacy of this procedure in controlling reflux with acceptable perioperative morbidity and mortality. ${ }^{1.9}$ However, GER can recur following fundoplication with a reported incidence ranging from $0 \%$ to $12 \% .^{1-9}$ Recurrent GER in this setting is usually secondary to loosening or disruption of the fundal wrap. The surgical management of children with this complication can be very challenging due to their generally poor nutritional status and to the frequent coexistence of neurological dysfunction with poorly controlled movement or seizure disorders that may predispose to wrap breakdown. Further, the dense intraabdominal adhesions that often develop following this type of surgery can complicate surgical repair of the disrupted fundoplication. Over the past 15 years, 35 children with Nissen fundoplication failures have been treated at the University of Michigan C.S. Mott Children's Hospital. We have studied this group of children in an effort to determine the role and success of the redo Nissen fundoplication in the management of wrap failure and recurrent GER.

\section{MATERIALS AND METHODS}

From January 1974 to January 1989, 286 children have been treated for GER with Nissen fundoplications at the C.S. Mott Children's Hospital. A review of the hospital records of these patients was performed. Two hundred forty-two of these children have been followed for an average of 30 months; the remaining 44 have been lost to follow-up. Since 1974, antireflux surgery at this institution has been standardized and consists of a Nissen fundoplication together with a posterior gastropexy as well as placement of a feeding gastrostomy in all mentally retarded children and all patients less than 2 years of age. ${ }^{10}$ Twenty-nine children (12\%) developed recurrent reflux following fundoplication, and an additional 6 patients who had undergone initial fundoplication at another institution were also treated for recurrent reflux following fundoplication failure. One other child treated at this hospital required redo fundoplication for a postoperative partial gastric volvulus causing gastric outlet obstruction. The sex, age, symptoms at the time of recurrence, physical condition, treatment, and outcome were reviewed for each child in this series. Follow-up data were obtained via clinic visits and phone contacts with patients' families.

\section{RESULTS}

Of the 36 paticnts with failure of their initial fundoplication, 22 were boys and 14 were girls, with age at the time of initial fundoplication ranging from 2 months to 20 years. Thirty-one of the 36 children were mentally retarded, and a seizure or movement 
disorder was documented in 21 of these children. Vomiting was the most common presenting symptom of recurrent reflux, which occurred an average of 14 months following the initial fundoplication (Table 1). Recurrent reflux in each child was documented with upper gastrointestinal radiography or esophageal $\mathrm{pH}$ monitoring using well-established criteria. ${ }^{9-11}$

For a variety of reasons, 16 of the children with recurrent reflux were treated medically with thickened upright feedings, continuous gastrostomy feedings, or enteral feedings through a fluoroscopically placcd gastrojejunal tubc (Table 2). Five of the patients died of coexistent medical problems within 2 months following documentation of recurrent reflux. All these children were severely debilitated, with recurrent reflux exacerbating their tenuous medical status. The remaining 11 patients treated nonoperatively have all done well with appropriate weight gain for age, elimination of aspiration, and reasonable control of reflux symptoms.

Nineteen children have required redo Nissen fundoplication for severe recurrent symptoms that could not be successfully managed medically, and one other child underwent redo fundoplication for an early postoperative gastric outlet obstruction. Of the 20 children who have undergone redo fundoplication, 16 are asymptomatic without GER at an average follow-up of 28 months. Intraoperative findings at the time of redo fundoplication are noted in Table 3 . The incidence of postoperative complications following the second fundoplication was $30 \%$ (Table 4). Four of these children have developed recurrent GER following their second fundoplication; 1 of these patients is doing well following her third fundoplication; 2 have been managed successfully with continuous gastrojejunal feedings, and the fourth child died of complications related to a recurrent tracheoesophageal fistula.

\section{DISCUSSION}

Recurrent GER is a well documented complication of the Nissen fundoplication with an incidence of $12 \%$ in this series of 242 children. The management of this complication is challenging because most of the children with recurrent reflux are malnourished and mentally retarded, with many having poorly

Table 1. Presenting Symptoms of Recurrent Reflux

\begin{tabular}{lc}
\hline \multicolumn{1}{c}{ Symptom } & No. of Children \\
\hline Vomiting & 28 \\
Aspiration & 3 \\
Failure to thrive & 3 \\
Posturing & 1 \\
Gastric obstruction & 1 \\
Total & 36 \\
\hline
\end{tabular}

Table 2. Indications for Nonoperative Management of Recurrent GER

\begin{tabular}{lc}
\hline \multicolumn{1}{c}{ Indication } & $\begin{array}{c}\text { No. of } \\
\text { Children }\end{array}$ \\
\hline Poorly controlled seizures & 10 \\
Poor operative risk & $5^{*}$ \\
Tolerated gastrojejunal feeds & 2 \\
Tolerated oral feedings & 1 \\
Asymptomatic; dilatable stricture & 1 \\
\hline
\end{tabular}

*Indicates 3 patients with seizures.

controlled movement or seizure disorders that may predispose to wrap disruption. ${ }^{12}$ Furthermore, operative correction with redo fundoplication is often technically challenging due to dense intraperitoneal adhesions that frequently develop after an initial antireflux procedure. Therefore, the risk of reoperation must be carefully considered prior to undertaking a second fundoplication.

Recurrent reflux following fundoplication may be secondary to a variety of anatomic and functional abnormalities. For adult patients, Hill et al ${ }^{11}$ classify fundoplication failures into failures due to: (1) a patulous or incompetent initial repair; (2) a slipped repair in which the wrap slips to encircle the stomach; (3) complete or partial disruption of the wrap; (4) gastroesophageal obstruction due to a tight wrap; and (5) intussusception of the gastric mucosa cephalad to the fundic wrap.

In the pediatric age group, wrap disruption appears to be the primary cause of recurrent reflux, with 14 of 20 reoperated patients in this series having wrap disruption documented intraoperatively as the cause of recurrent reflux. These data are supported by other large series in which wrap disruption was the primary etiology for recurrent reflux ${ }^{1.3}$ Paraesophageal herniation has also been noted following pediatric fundoplication, ${ }^{1,2,13,14}$ although only 4 patients in this group of 242 patients had this complication documented. These were all small hernias and, because all 4 patients were asymptomatic, operative intervention was not considered necessary.

The causes of wrap disruption following fundoplication remain speculative. The concept of "recurrence risk factors" has been suggested for adults, ${ }^{15}$ and

Table 3. Intraoperative Findings at the Time of Redo Fundoplication

\begin{tabular}{cc}
\hline Intraoperative Findings & $\begin{array}{c}\text { No. of } \\
\text { Children }\end{array}$ \\
\hline Wrap disruption & 14 \\
Patulous wrap & 2 \\
Hiatal hernia & 2 \\
Slipped wrap & 1 \\
Gastric volvulus & 1 \\
Total & 20 \\
\hline
\end{tabular}


Table 4. Complications Following Redo Fundoplication in 20 Children

\begin{tabular}{lc}
\hline \multicolumn{1}{c}{ Corrolication } & $\begin{array}{c}\text { No. of } \\
\text { Children }\end{array}$ \\
\hline Bleeding gastric ulcer & 1 \\
Small bowel obstruction & 2 \\
Gastric leak & 1 \\
Intraabdominal abscess & 1 \\
Wound infection & 1 \\
Total & 6 \\
\hline
\end{tabular}

seems valid for children as well. In this series, 31 of 36 children with recurrent reflux were mentally retarded, with two-thirds of this group having severe seizure disorders. In addition, severe pulmonary dysfunction was present in over $40 \%$ of patients with recurrent reflux. These findings have been strongly confirmed by other investigators, ${ }^{1,3}$ who have suggested that mental retardation, presence of a seizure disorder, and presence of pulmonary insufficiency are all recurrence risk factors for children following antireflux surgery.

In addition to these risk factors, severe technical points have been implicated as contributing to fundoplication failure. Inadequate mobilization of the gastroesophageal junction, fundus, and cardia is thought to increase the risk of wrap disruption, particularly in children with increased abdominal pressure due to movement disorders, aerophagia, or constipation. ${ }^{1-3}$ Dedinsky et al also emphasize the importance of limiting the wrap length to 3 to $4 \mathrm{~cm}$ of intraabdominal esophagus with minimal downward traction on the thoracic esophagus to prevent herniation of an elongated wrap into the mediastinum. ${ }^{1}$ Finally, an accurate crural repair has been clearly demonstrated as critical to a successful fundoplication. Paraesophageal herniation, often accompanied by reflux, can occur following Nissen fundoplication and appears related to failure to perform an adequate crural repair. ${ }^{2,13,14}$ The authors routinely perform a posterior gastropexy and crural reapproximation in all fundoplications and have had a $2 \%$ incidence of paraesophageal herniation. The importance of crural reapproximation can not be overemphasized.

The etiology of the increased Nissen failure rate among children with neurological impairment has not been well elucidated. Poorly controlled seizures, constipation, and aerophagia all may predipose to wrap disruption by raising intraabdominal pressure. We attempt to optimize seizure control and pulmonary toilet preoperatively and to routinely place gastrostomy tubes in all mentally retarded patients both to augment nutrition and to prevent "gas bloating" and wrap distention in the early postoperative period. Recently, a strong correlation between GER and delayed gastric emptying has been documented in neurologically impaired children, with evidence suggesting that delayed gastric emptying may predispose to postoperative wrap failure as well as early satiety, bloating, and gagging following fundoplication. ${ }^{16.17}$ A pyloroplasty in conjunction with fundoplication is indicated when delayed gastric emptying is demonstrated preoperatively, and it is now planned to evaluate neurologically impaired children undergoing fundoplication with preoperative radionuclide gastric scintography.

The management of recurrent reflux is difficult. For children with poorly controlled seizures or with concurrent illnesses that place them at markedly increased operative risk, recurrent reflux has been initially treated conservatively with either continuous feedings through a fluoroscopically placed gastrojejunal tube or with upright, thickened oral feedings. These methods have allowed successful nonoperative management of 11 of the 36 children with recurrent reflux.

Without question, surgical management with a second Nissen fundoplication is preferred for children without multiple concurrent medical problems and for higher-risk children in whom conservative management has been unsuccessful. Of the 20 children who underwent redo fundoplications, $16(80 \%)$ have had good results with elimination of reflux symptoms. Standard operative principles including the avoidance of wrap tension, creation of an accurate crural repair, and treatment of concurrent gastric stasis with pyloroplasty are essential for the success of a second fundoplication. A transabdominal rather than transthoracic approach is preferred for redo fundoplication surgery because it is generally less morbid with success rates comparable to those reported for transthoracic repairs in adults. ${ }^{15}$ Despite the technical difficulties of such a procedure, these data as well as those from other pediatric surgical centers document that satisfying results can be achieved with redo fundoplication for recurrent reflux. ${ }^{1-3}$

Recurrent GER following Nissen fundoplication occurs frequently and is generally related to wrap disruption. Risk factors for fundoplication failure include neurological impairment, pulmonary disease, and the presence of a seizure disorder. Conservative management should be considered in the initial treatment of high-risk children with recurrent GER. If necessary, redo fundoplication is associated with a good outcome in the majority of children, and is indicated for refractory recurrent GER following a failed antireflux procedure. 


\section{REFERENCES}

1. Dedinsky GK, Vane DW, Black CT, et al: Complications and reoperation after Nissen fundoplication in childhood. Am J Surg 153:177-183, 1987

2. Tunell WP, Smith EI, Carson JA: Gastroesophageal reflux in childhood: The dilemma of surgical success. Ann Surg 197:560-565, 1983

3. Randolph J: Experience with the Nissen fundoplication for correction of gastroesophageal reflux in infants. Ann Surg 198:579584,1983

4. St. Cyr JA, Ferrara TB, Thompson TR, et al: Nissen fundoplication for gastroesophageal reflux in infants. $J$ Thorac Cardiovasc Surg 92:661-666, 1986

5. Vane DW, Harmel RP, King DR, et al: The effectiveness of Nissen fundoplication in neurologically impaired children with gastroesophageal reflux. Surgery 98:662-666, 1985

6. Bettex M, Kuffer F: Long-term results of fundoplication in hiatus hernia and cardio-esophageal chalasia in infants and children: Report of 112 consecutive cases. J Pediatr Surg 4:526-530, 1969

7. Carcassonne M, Guys JM, Delarue A, et al: Surgery of gastroesophageal reflux. World J Surg 9:269-276, 1985

8. Fonkalsrud EW, Ament ME, Berquist W: Surgical management of the gastroesphageal reflux syndrome in childhood. Surgery 97:42-48, 1985

9. Turnage RH, Oldham KT. Coran AG, et al: Late results of fundoplication for gastroesophageal reflux in infants and children. Surgery 105:457-464, 1989

10. Wesley JR, Coran AG, Sarahan TM, et al: 'l the need for evaluation of gastroesophageal reflux in brain-damaged children referred for feeding gastrostomy. I Pediatr Surg 16:866-871, 1981

11. Hill LD, Ilves R, Stevenson JK, et al: Reoperation for disruption and recurrence after Nissen fundoplication. Arch Surg 114:542-548, 1979

12. Blane CE, Klein MD, Drongowski RA, et al: Gastroesophageal reflux in children: Is there a place for the upper gastrointestinal study? Gastrointest Radiol 11:346-348, 1986

13. Alrabeeah A, Giacomantonio M. Gillis DA: Paraesophageal hernia after Nissen fundoplication: A real complication in pediatric patients. J Pediatr Surg 23:766-768, 1988

14. Festen C: Paraesophageal hernia: A major complication of Nissen fundoplication. J Pediatr Surg 16:496-499, 1981

15. Stirling MC, Orringer MB: Surgical treatment after the failed antireflux operation. J Thorac Cardiovasc Surg 92:667-672. 1986

16. Papaila JG, Wilmot D, Grosfeld JL, et al: Increased incidence of delayed gastric emptying in children with gastroesophageal reflux: A prospective evaluation. Arch Surg 124:933-936, 1989

17. Maddern GJ, Jamieson GG, Chatterton BE, et al: Is there an association between failed antireflux procedures and delayed gastric emptying? Ann Surg 202:162-165, 1985 